\title{
Dietary Calcium Intake and Rates of Bone Loss in Women
}

B. Lawrence Riggs, Heinz W. Wahner, L. Joseph Melton III, Linda S. Richelson, Howard L. Judd, “ and W. Michael O’Fallon Endocrine Research Unit, Division of Endocrinology, Metabolism, and Internal Medicine, Section of Diagnostic Nuclear Medicine, and Department of Medical Statistics and Epidemiology, Mayo Clinic and Mayo Foundation, Rochester, Minnesota 55905; and *University of California at Los Angeles, School of Medicine, Center for the Health Services, Los Angeles, California 90024

\begin{abstract}
We measured bone mineral density (BMD) at the midradius and lumbar spine in 106 normal women, ages 23-84 yr (61 were postmenopausal). Three to nine measurements (median, four) were made over 2.6 to $6.6 \mathrm{yr}$ (mean, $4.1 \mathrm{yr}$ ). The correlation between calcium intake (range, $260-2,035 \mathrm{mg} / \mathrm{d}$ ) and rate of change in BMD was not significant at the midradius ( $r$ $=0.06)$ or lumbar spine $(r=0.08)$, even after adjusting for age, menopausal status, and serum estrogen levels by multiple regression analysis. Women in the lower (mean, $501 \mathrm{mg} / \mathrm{d}$ ) and in the upper (mean, $1,397 \mathrm{mg} / \mathrm{d}$ ) quartiles of dietary intake had similar rates of change in BMD $(\% / y r$ [mean \pm SE], at midradius, $-0.78 \pm 0.24$ and $-0.91 \pm 0.17$ for lower and upper quartiles, respectively; at lumbar spine, $-1.06 \pm 0.24$ and $-0.98 \pm 0.24)$. These data do not support the hypothesis that insufficient dietary calcium is a major cause of bone loss in women.
\end{abstract}

\section{Introduction}

When calcium absorbed from the diet is insufficient to offset obligatory fecal and urinary losses, calcium must be withdrawn from bone, which contains $99 \%$ of total body calcium stores (1). Several investigators consider insufficiency of dietary calcium intake or of calcium absorption to be major risk factors for the development of osteoporosis $(2,3)$. Although the recommended daily allowance for calcium is set at 800 $\mathrm{mg} / \mathrm{d}$ (4), middle-aged and elderly American women have a mean intake of only $500 \mathrm{mg} / \mathrm{d}(5)$.

Additionally, the Consensus Conference on Osteoporosis from the National Institutes of Health recommended that calcium intake be increased to $1,000 \mathrm{mg} / \mathrm{d}$ for premenopausal women and to $1,500 \mathrm{mg} / \mathrm{d}$ for postmenopausal women (6). This recommendation has received a great deal of attention in the media, and it is estimated that sales of calcium tablets in the United States should reach $\$ 166$ million in 1987 , an approximate doubling of sales in the last two years (7).

Despite this popular enthusiasm, experimental studies documenting the role of calcium deficiency in the pathogenesis of osteoporosis and the value of calcium supplementation in the

Address correspondence and reprint requests to Dr. B. Lawrence Riggs, Endocrine Research Unit, Division of Endocrinology, Metabolism, and Internal Medicine, Mayo Clinic, 200 First Street SW, Rochester, MN 55905. 1987.

Received for publication 31 July 1986 and in revised form 27 April

J. Clin. Invest.

(c) The American Society for Clinical Investigation, Inc

0021-9738/87/10/0979/04 \$2.00

Volume 80, October 1987, 979-982 prevention of it have given conflicting results. Using metabolic balance methods, Nordin et al. (8) estimated that a calcium intake of $550 \mathrm{mg} / \mathrm{d}$ was required to prevent negative calcium balance. In contrast, Heaney et al. (9) estimated with combined radiocalcium kinetic and calcium balance studies that daily requirements were $1,000 \mathrm{mg}$ for premenopausal women and $1,500 \mathrm{mg}$ for postmenopausal women. In a large crosssectional survey, Garn (10) found no relationship between metacarpal cortical area and calcium intake. Matkovic et al. (11) found lower values for this cortical area in a Yugoslavian district with low calcium intake than in another district with a high intake. These differences were apparent in young adult bone and did not become larger with aging, suggesting that the main effect of calcium intake was during bone growth. Nilas et al. (12) found no relationship in postmenopausal women between rate of bone loss from the distal radius and dietary calcium consumption over a wide range of intakes. Four of six clinical trials (13-18) found significant short-term slowing of bone loss from the appendicular skeleton when postmenopausal women received calcium supplements of at least 750 $\mathrm{mg} / \mathrm{d}$. In those trials in which a significant effect of calcium supplementation was demonstrated, however, the degree of retardation of bone loss was less than that achieved by estrogen administration $(14,15,17)$. More recently, however, two studies $(19,20)$ found that administration of $1,500 \mathrm{mg} / \mathrm{d}$ of calcium supplements for $2 \mathrm{yr}$ did not decrease rate of bone loss from lumbar spine as compared with a placebo-treated group of women in the immediate postmenopausal period.

Because of this uncertainty, we evaluated the relationship between dietary calcium intake and rates of change in bone in the axial and appendicular skeleton in normal women of various ages.

\section{Methods}

Experimental subjects and protocol. We measured bone mineral density (BMD) ${ }^{1}$ at the midradius and lumbar spine in 106 normal women who were residents of Rochester, MN. Of these, 73 were from a stratified random sample selected from the community population as part of an ongoing epidemiologic study (group A). All subjects from the random sample were included provided they had been followed for $>2.5 \mathrm{yr}$, had at least three densitometry measurements, and had none of the exclusion criteria. The remainder were volunteers from the same population (group B). Mean age was $52 \mathrm{yr}$ (range, 23-84 yr), and 61 were postmenopausal. Menopause was defined as absence of menses for at least $6 \mathrm{mo}$ and serum estradiol level $<50 \mathrm{pg} / \mathrm{ml}$. Normality was assessed by interview, review of each patient's medical record, and laboratory testing. All had normal values for serum calcium, phosphorus, creatinine, and alkaline phosphatase. All subjects were ambulatory. None had vertebral fractures on roentgenograms of the spinal column or a history of hip fracture. None was taking corticosteroids, anticonvulsive medication, thiazide diuretics, vitamin $\mathrm{D}$ in pharmaco-

1. Abbreviation used in this paper: BMD, bone mineral density. 
logic dosages, or calcium supplement of $>500 \mathrm{mg} / \mathrm{d}$. None of the postmenopausal women was taking estrogen replacement therapy. Five of the premenopausal women were taking contraceptive hormones. None had any evident medical disease known to affect calcium metabolism. These exclusion criteria were maintained for the duration of the study.

Dietary calcium intake was assessed by a trained dietitian who interviewed each patient for $1 \mathrm{~h}$ and reviewed a 7-d dietary diary recorded by the subject. The dietary survey was made at the beginning of the period of observation of the 73 subjects in group A, whereas it was obtained at the end for the subjects in group B. Reproducibility of the estimate of the dietary calcium intake was assessed by repeating the interview and the 7-d dietary diary after an interval of $2 \mathrm{yr}$ in 22 subjects ( 12 of these were in the present study and 10 were members of the ongoing epidemiologic study but were not included because they did not meet the criteria for normality). Stability of calcium intake over the period of study was assessed by a questionnaire on use of dairy products and calcium supplements (the principal sources of calcium in the diet). In the patients in the epidemiologic study, the questionnaire was completed at the end of the study and was compared with comparable items obtained by the dietitian's interview. In the remaining subjects, the stability of the calcium intake was assessed by comparing these same items in the dietary calcium interview obtained at the end of the study with estimates by the dietitian of use of these items at the beginning of the study.

Fasting-state blood samples were drawn for determination of serum sex steroid levels. For the premenopausal women, the blood sample was obtained between days 7 and 10 of the menstrual cycle. Bone densitometry was repeated on one or more occasions. The interval between the first and last measurements ranged from 2.6 to $6.6 \mathrm{yr}$ (median, $4.1 \mathrm{yr}$ ). The number of measurements per subject ranged from three to nine (median, four measurements).

All subjects gave their informed consent. The experimental protocol was reviewed and approved by the Mayo Institutional Review Board. Descriptive characteristics of the experimental subjcts are given in Table $\mathrm{I}$.

Laboratory methods. BMD of the midradius was measured by single-photon absorptiometry as described (21) except that the scanner was modified to permit rectilinear scanning. The recorded value was the mean of five scan passes at intervals of $0.1 \mathrm{~cm}$. Reproducibility ([SD/mean of repeat measurements] $\times 100$ ) was $1 \%$. BMD of the lumbar spine was measured by dual-photon absorptiometry (22); reproducibility was $1.7 \%(23)$. Serum estrone and estradiol were measured by described radioimmunoassay techniques (24).

Statistical methods. To estimate rates of BMD change, a linear regression was fitted for each patient. These regressions used BMD as the dependent variable and time, in years, from the patient's entry into the study as the independent variable. The slope was expressed as $\mathrm{g} / \mathrm{cm}^{2}$ per $\mathrm{yr}$ and $\mathrm{g} / \mathrm{cm}$ per $\mathrm{yr}$ for the lumbar spine and midradius sites, respectively. Each slope was divided by the predicted BMD value at the midpoint of the time interval for which the patient was under study and multiplied by 100 to obtain the percent change per year $(\% / y r)$. The slopes and the percentage change per year are highly correlated ( $r$ $=0.984$ for midradius and $r=0.981$ for lumbar spine). Thus, we elected to express results as percent change per year for the sake of simplicity.

To evaluate the association between dietary calcium intake and rate of BMD change (\%/yr), we examined both the overall relationship as well as the adjusted effect after controlling for other significant variables. To assess the overall relationship, zero-order correlation was used. The sample was also divided into four groups by quartile of calcium intake and rates of BMD change were compared across groups. To assess the adjusted effect of calcium intake on rates of BMD change, we first used stepwise multiple regression with backward elimination to select significant control variables before the inclusion of calcium intake in the model. In the process of variable selection, as well as in the final model, various interaction terms and the distribution of residuals were examined, and the assumptions of normality and homoskedasticity of the residuals were verified for each of them. The
Table I. Characteristics of Experimental Subjects Expressed as Mean $\pm S D$ and Range of Values

\begin{tabular}{lccc}
\hline & All subjects & Premenopausal & Postmenopausal \\
\hline Number of subjects & 106 & 45 & 61 \\
Age $(y r)$ & $53.9 \pm 13.9$ & $40.6 \pm 6.2$ & $63.7 \pm 9.0$ \\
& $(25.2-86.1)$ & $(25.2-55.0)$ & $(48.4-86.1)$ \\
Calcium intake $(g)$ & $922.4 \pm 355.3$ & $991.0 \pm 393.9$ & $871.8 \pm 317.9$ \\
& $(260-2,003)$ & $(289-2,003)$ & $(260-1,743)$ \\
Rate of loss $(\% / y r)$ & & & \\
Midradius & $-0.81 \pm 1.16$ & $-0.10 \pm 0.75$ & $-1.32 \pm 1.13$ \\
& $(-4.23-1.94)$ & $(-1.43-1.55)$ & $(-4.23-1.94)$ \\
Lumbar spine & $-1.05 \pm 1.24$ & $-0.89 \pm 1.15$ & $-1.16 \pm 1.30$ \\
& $(-4.33-1.91)$ & $(-3.92-1.22)$ & $(-4.33-1.91)$ \\
Serum estradiol & $58.4 \pm 77.3$ & $117.6 \pm 89.2$ & $14.7 \pm 6.8$ \\
$(\mathrm{pg} / \mathrm{ml})$ & $(3-367)$ & $(7-367)$ & $(3-39)$ \\
Serum estrone & $39.7 \pm 31.3$ & $60.7 \pm 37.8$ & $24.1 \pm 9.3$ \\
$(\mathrm{pg} / \mathrm{ml})$ & $(7-204)$ & $(19-204)$ & $(7-54)$ \\
& & & \\
\hline
\end{tabular}

adjusted effect of calcium intake on rates of BMD change was then assessed by partial correlation. To account for the differences in follow-up time and number of bone measurements associated with individual rates of changes in BMD, regression analysis was weighted by the inverse of the corresponding variances of these rates (equal to the sum of the inter- and intrasubject variances) (25).

\section{Results}

Calcium intake. There was a normal distribution for total intake of dietary calcium; mean $\pm \mathrm{SD}$ was $922 \pm 355 \mathrm{mg} / \mathrm{d}$ (range, $260-2,003 \mathrm{mg} / \mathrm{d})$. For the 22 subjects who had a repeat assessment of calcium intake, the baseline measurement (mean $\pm \mathrm{SE}$ ), $891 \pm 76 \mathrm{mg} / \mathrm{d}$, and the 2 -yr repeat measurement, $1,011 \pm 118 \mathrm{mg} / \mathrm{d}$, did not differ significantly. The main sources of calcium intake (dairy products and supplemental calcium tablets) also did not change significantly between the beginning, $574 \pm 37 \mathrm{mg} / \mathrm{d}$, and the end, $558 \pm 33 \mathrm{mg} / \mathrm{d}$, of the study.

Bone densitometry. The overall rates of BMD change for both the midradius and the lumbar spine were normally distributed with means $( \pm \mathrm{SD})$ of $-0.81 \% \pm 1.16 \%$ and $-1.05 \% \pm 1.24 \%$ per yr, respectively. Calcium intake and rate of change in BMD were not correlated at the midradius ( $r$ $=-0.04, \mathrm{NS})$ or at the lumbar spine $(r=0.08, \mathrm{NS})$. Individual values for this relationship are shown in Figs. 1 and 2. Women in the lower (mean, $501 \mathrm{mg} / \mathrm{d}$ ) and upper (mean, 1,397 mg/d) quartiles of dietary calcium intake had similar rates of change in BMD (\%/yr [mean \pm SE], at midradius, $-0.78 \pm 0.24$ and $-0.91 \pm 0.17$ for lower and upper quartiles, respectively; at lumbar spine, $-1.06 \pm 0.24$ and $-0.98 \pm 0.24$ ).

Table II summarizes the multiple regression models used to control the effects of potentially confounding variables on

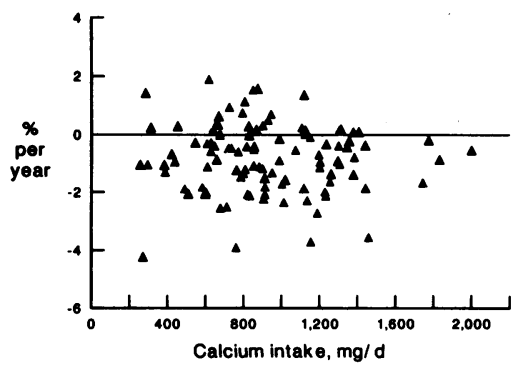

Figure 1. Relationship of rate of change in BMD (\%/yr) at midradius to estimated dietary calcium intake in 106 normal women. 


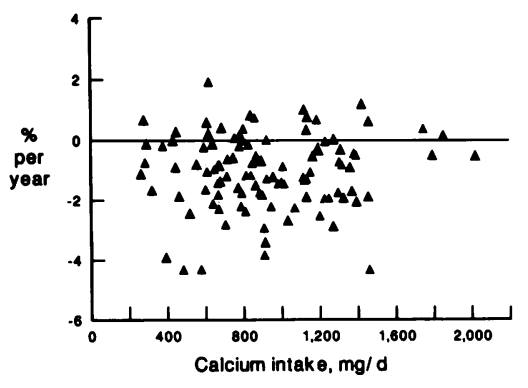

Figure 2. Relationship of rate of change in BMD (\%/yr) at lumbar spine to estimated dietary calcium intake in 106 normal women.

the relationship between rate of BMD change and calcium intake. The model was adjusted for these variables by entering each term into it and adjusting accordingly before testing for an effect of calcium intake on rates of change in BMD using partial correlation coefficients. The variables considered for this model were age, age squared, serum estrone, serum estradiol, and menopausal status. The square of age was included because in a previous study (20) we found that the rate of BMD change for the lumbar spine was related to age in a parabolic fashion. For lumbar spine, the interaction of age and menopausal status was significant. For midradius, the agesquared term and its interaction with menopause were significant in a model of age, age-squared, menopausal status, and two-way interactions. The interaction terms between age and menopausal status indicated that the effects of age on the rate of BMD change were different between pre- and postmenopausal women. Thus, the effect of calcium intake was assessed separately in pre- and postmenopausal women. Of course, once menopausal status was taken into account, the values for serum estrone and estradiol were not significant because both were highly correlated with menopausal status $(r=-0.58, P$ $<0.001$ for serum estrone; $r=-0.66, P<0.001$ for serum estradiol).

Calcium intake was then incorporated into the regression model for rate of change by menopausal status. For midradius, there was a marginally significant trend $(P=0.08)$ for an inverse correlation between change in BMD and calcium intake in the premenopausal women (the higher the intake the more negative the rate of change). For lumbar spine, there was no suggestion of a relationship for either pre- or postmenopausal women. Thus, even after controlling for all salient variables, a significant relationship between calcium intake and

Table II. Influence of Calcium Intake on Rate of BMD Change (\% of Mean/Yr) at Midradius and Lumbar Spine, by Menopausal Status with Adjustment for Effect of Age: Results of Weighted Analysis

\begin{tabular}{|c|c|c|c|c|c|}
\hline \multirow[b]{2}{*}{ Site } & \multirow[b]{2}{*}{$\begin{array}{l}\text { Menopausal } \\
\text { status }\end{array}$} & \multicolumn{2}{|c|}{ Age model* } & \multicolumn{2}{|c|}{$\begin{array}{l}\text { Additional effect } \\
\text { of calcium intake }\end{array}$} \\
\hline & & $R^{2}$ & $P$ & $r$ & $P$ \\
\hline \multirow[t]{2}{*}{ Midradius } & Pre- & 0.214 & 0.006 & -0.272 & 0.08 \\
\hline & Post- & 0.001 & 0.89 & -0.134 & 0.31 \\
\hline \multirow[t]{2}{*}{ Lumbar spine } & Pre- & 0.249 & 0.001 & 0.133 & 0.39 \\
\hline & Post- & 0.001 & 0.77 & -0.024 & 0.85 \\
\hline
\end{tabular}

Weighting factor is the inverse of the sum of intrasubject variance and intersubject variance.

* For premenopausal group at midradius, the age model includes the square of age. rate of change in BMD could not be demonstrated for either the midradius or lumbar spine.

Table III gives the power calculations for the ability of the model to detect these changes. The values presented are the values for $\rho$, the population correlation coefficient, which if these or higher values existed would yield statistically significant results 80 or $90 \%$ of the time (assuming that the samples of the sizes actually in hand were used to test the hypothesis of no association at $\alpha=0.05$ ). These values have been adjusted for measurement errors, i.e., the proportion of intrasubject variance in relation to intersubject variance for both rate of change in BMD and calcium intake. The intra- and intersubject variance of calcium intake were estimated based on 12 subjects with repeated measurements. The shares of intra- and intersubject variance are about 52 vs. $48 \%$ for rate of change in lumbar spine, 57 vs. $48 \%$ for midradius and 20 vs. $80 \%$ for calcium intake.

\section{Discussion}

Our data do not support the hypothesis that the rate of bone loss in adult women has a major relationship to dietary calcium intake over the wide range of values found in the normal American diet. If such a major relationship were present, we believe that it would have been detected by our experimental design. First, the bone densitometry methods that we used were highly precise, and we observed individual subjects for a sufficient interval to obtain a good estimate of individual rate of change in the axial and the appendicular skeleton. Second, we assessed calcium intake by combining two reliable survey methods-interview by a trained dietitian and 7-day food diary. Using a somewhat less precise method, we found that the mean intake of dairy products and calcium supplements, the two major sources of calcium, did not change during the study interval. Third, we controlled for the potentially con-

Table III. Power Calculations for Detection of Correlations between Rates of Change in BMD and Dietary

Calcium Intake When $\alpha=0.05$,

Adjusted for Measurement Errors

\begin{tabular}{|c|c|c|c|}
\hline & \multicolumn{3}{|l|}{$\underline{\rho}$} \\
\hline & All subjects & Premenopausal & Postmenopausal \\
\hline Number of subjects & 106 & 45 & 61 \\
\hline \multicolumn{4}{|l|}{ Midradius } \\
\hline \multicolumn{4}{|c|}{ Power to detect $=0.8$} \\
\hline Simple & 0.43 & 0.65 & 0.57 \\
\hline Partial & 0.45 & 0.67 & 0.58 \\
\hline \multicolumn{4}{|c|}{ Power to detect $=0.9$} \\
\hline Simple & 0.50 & 0.73 & 0.65 \\
\hline Partial & 0.52 & 0.75 & 0.65 \\
\hline \multicolumn{4}{|l|}{ Lumbar spine } \\
\hline \multicolumn{4}{|c|}{ Power to detect $=0.8$} \\
\hline Simple & 0.41 & 0.62 & 0.54 \\
\hline Partial & 0.43 & 0.64 & 0.56 \\
\hline \multicolumn{4}{|c|}{ Power to detect $=0.9$} \\
\hline Simple & 0.48 & 0.70 & 0.62 \\
\hline Partial & 0.49 & 0.71 & 0.62 \\
\hline
\end{tabular}

Adjusted for the proportion of intrasubject variance in relation to intersubject variance. 
founding effects of age, menopause, and serum estrogen levels by multiple regression analysis.

Our calculations indicate that we had sufficient power to detect a strong relationship between calcium intake and bone loss, had such a relationship existed. We cannot exclude the possibility of a weak relationship that was not detected. The complete absence of any trend for a positive correlation between rate of change in BMD and dietary calcium intake, however, argues against the existence of a major physiologic relationship.

Our results differ from the preliminary longitudinal results obtained by Aloia et al. (26), who measured total body calcium by neutron activation analysis and bone density of midradius by photon absorptiometry at baseline and after 1 yr in 44 women in the immediate postmenopause period. They found a weak correlation of estimated dietary calcium intake with rate of loss of total body calcium but no correlation with midradius bone loss.

Several caveats must be considered in interpreting these data. First, our results are relevant only to adult women. We did not study the possibility that variation in dietary calcium intake during the adolescent growth spurt may influence peak bone mass (11). Second, because patients with vertebral or hip fractures were excluded from the study, we did not evaluate the possibility that some patients develop osteoporosis because of calcium deficiency. Nonetheless, because there is a continuum of bone density values between age-matched normal women and patients with postmenopausal osteoporosis (20), our results probably are relevant to the process by which osteoporosis develops. Finally, because only four of our subjects had a total calcium intake of more than $1,500 \mathrm{mg} / \mathrm{d}$, we cannot exclude the possibility that larger doses of calcium (with or without vitamin D) would decrease the rate of bone loss (27, 28). Thus, the questions of the relationship of dietary calcium to bone loss and the value of high calcium intake in prevention of osteoporosis should be considered open, and further studies should be conducted. Studies relating the amount of absorbed calcium to bone loss in women of various ages and assessing the effect of calcium supplements on rates of bone loss from the vertebrae are particularly needed.

\section{Acknowledgments}

We thank Ms. Willana Klause for her dedicated work in obtaining the dietary calcium histories which were critical to a successful outcome for this study. We also thank Stephen H. Kan, Ph.D., for his assistance in statistical analysis of data and Ms. Cheryl K. Collins for typing the manuscript.

This work was supported in part by Research Grant AM-27065 from the National Institutes of Health, Public Health Service.

\section{References}

1. Heaney, R. P., J. C. Gallagher, C. C. Johnston, R. Neer, A. M. Parfitt, and G. D. Whedon. 1982. Calcium nutrition and bone health in the elderly. Am. J. Clin. Nutr. 36:986-1013.

2. Heaney, R. P. 1982. Calcium intake requirement and bone mass in the elderly. J. Lab. Clin. Med. 100:309-312.

3. Nordin, B. E. C., A. G. Need, H. A. Morris, and M. Horowitz. 1985. New approaches to the problems of osteoporosis. Clin. Orthop. Relat. Res. 200:181-197.

4. National Research Council, Food and Nutrition Board. 1974. Recommended Dietary Allowances. 8th ed. National Academy Science, Washington, DC.

5. Consumer Nutrition Center. 1980. Food and nutrient intakes of individuals in 1 day in the United States, spring, 1977. Nationwide
Food Consumption Survey 1977-1978, Preliminary Report No. 2. United States Department of Agriculture, Hyattsville, MD.

6. Consensus Conference. 1984. Osteoporosis. J. Am. Med. Assoc. 252:799-802.

7. Bishop, J. E. America's new hunger for calcium presents a nutritional dilemma. The Wall Street Journal. 1986 Jan. 20:17.

8. Nordin, B. E. C., A. Horsman, D. H. Marshall, M. Simpson, and G. M. Waterhouse. 1979. Calcium requirement and calcium therapy. Clin. Orthop. Relat. Res. 140:216-239.

9. Heaney, R. P., R. R. Recker, and P. D. Saville. 1978. Menopausal changes in calcium balance performance. J. Lab. Clin. Med. 92:953-963.

10. Garn, S. M. 1970. The Earlier Gain and the Later Loss of Cortical Bone. C. C. Thomas, Springfield, IL.

11. Matkovic, V., K. Kostial, I. Simonovic, R. Buzina, A. Brodarec, and B. E. C. Nordin. 1979. Bone status and fracture rates in two regions of Yugoslavia. Am. J. Clin. Nutr. 32:540-549.

12. Nilas, L., C. Christiansen, P. Rødbro. 1984. Calcium supplementation and postmenopausal bone loss. Br. Med. J. 289:1 103-1106.

13. Albanese, A. A., A. H. Edelson, E. J. Lorenze, M. L. Woodhull, and E. H. Wein. 1975. Problems of bone health in elderly. NY State J. Med. 75:326-336.

14. Recker, R. R., P. D. Saville, and R. P. Heaney. 1977. Effect of estrogens and calcium carbonate on bone loss in postmenopausal women. Ann. Intern. Med. 87:649-655.

15. Nordin, B. E. C., A. Horsman, R. G. Crilly, D. H. Marshall, and M. Simpson. 1980. Treatment of spinal osteoporosis in postmenopausal women. Br. Med. J. 280:451-453.

16. Smith, E. L., Jr., W. Reddan, and P. E. Smith. 1981. Physical activity and calcium modalities for bone mineral increase in aged women. Med. Sci. Sports. 13:60-64.

17. Horsman, A., J. C. Gallagher, M. Simpson, and B. E. C. Nordin. 1977. Prospective trial of oestrogen and calcium in postmenopausal women. Br. Med. J. 2:789-792.

18. Lamke, B., H. E. Sjoberg, and M. Sylven. 1978. Bone mineral content in women with Colles' fracture: effect of calcium supplementation. Acta Orthop. Scand. 49:143-146.

19. Ettinger, B., H. K. Genant, and C. E. Cann. 1985. Long-term estrogen replacement therapy prevents bone loss and fractures. Ann. Intern. Med. 102:319-324.

20. Riis, B., K. Thomsen, and C. Christiansen. 1987. Does calcium supplementation prevent postmenopausal bone loss? A double-blind, controlled clinical study. N. Engl. J. Med. 316:173-177.

21. Wahner, H. W., B. L. Riggs, and J. W. Beabout. 1977. Diagnosis of osteoporosis: usefulness of photon absorptiometry at the radius. J. Nucl. Med. 18:432-437.

22. Riggs, B. L., H. W. Wahner, W. L. Dunn, R. B. Mazess, K. P. Offord, and L. J. Melton III. 1981. Differential changes in bone mineral density of the appendicular skeleton with aging: relationship to spinal osteoporosis. J. Clin. Invest. 67:328-335.

23. Riggs, B. L., H. W. Wahner, L. J. Melton III, L. S. Richelson, H. L. Judd, and K. P. Offord. 1986. Rates of bone loss in the appendicular and axial skeletons of women. Evidence of substantial vertebral bone loss before menopause. J. Clin. Invest. 77:1487-1491.

24. Judd, H. L., G. E. Judd, W. E. Lucas, and S. S. C. Yen. 1974. Endocrine function of the postmenopausal ovary: concentrations of androgens and estrogens in ovarian and peripheral vein blood. J. Clin. Endocrinol. Metab. 39:1020-1024.

25. Laird, N. M., and J. H. Ware. 1982. Random effects models for longitudinal data. Biometrics. 38:963-974.

26. Aloia, J. F., A. N. Vaswani, J. K. Yeh, P. Ross, K. Ellis, and S. H. Cohn. 1983. Determinants of bone mass in postmenopausal women. Arch. Intern. Med. 143:1700-1704.

27. Schwartz, E., V. A. Panariello, and J. Saeli. 1965. Radioactive calcium kinetics during high calcium intake in osteoporosis. J. Clin. Invest. 44:1547-1560.

28. Riggs, B. L., J. Jowsey, P. J. Kelly, D. L. Hoffman, and C. D. Arnaud. 1976. Effects of oral therapy with calcium and vitamin D in primary osteoporosis. J. Clin. Endocrinol. Metab. 42:1139-1144. 